\title{
Carotid Body
}

National Cancer Institute

\section{Source}

National Cancer Institute. Carotid Body. NCI Thesaurus. Code C66852.

A cluster of cells that function as chemo-receptors, located at the bifurcation of the carotid artery. Its main purpose is to detect changes in the composition of arterial blood. 